\title{
Acoustic characteristics of carbon fiber-reinforced synthetic wood for musical instrument soundboards
}

\author{
Teruaki Ono and Daisuke Isomura \\ Department of Mechanical and Systems Engineering, Faculty of Engineering, Gifu University, \\ 1-1 Yanagido, Gifu city, Gifu, 501-1193 Japan
}

(Received 8 January 2004, Accepted for publication 11 June 2004 )

Keywords: Frequency response, Vibrational properties, Carbon fiber, Polyurethane foam, CF/UF composite PACS number: 43.75.De, 43.75.Gh, 43.75.Mn [DOI: 10.1250/ast.25.475]

\section{Introduction}

The tone of wooden musical instruments, such as the violin family, guitars, and pianos, is strongly dependent on humidity, and musicians pay a great deal of attention to maintaining good tone. Only good quality wood of the Picea genus is used to make the top plates and soundboards of wooden musical instruments. However, obtaining such woods is becoming increasingly difficult due to problems with limited environmental resources. In addition, wood quality varies widely as wood is a biomaterial, and so it is necessary for musical instrument makers to invest a great deal of effort in quality control and in the wood drying process. To resolve these issues, we have begun the development of synthetic wood for use in musical instrument soundboards. Such synthetic wood would make it possible to supply materials with optional and stable properties, therefore improving existing musical instruments and creating new instruments.

Our first goal was to produce a synthetic material with similar acoustic properties to wooden soundboards and increased stability against humidity. Unidirectional carbon fiber-reinforced polyurethane foam composite, $(\mathrm{CF} / \mathrm{UF})_{\mathrm{L}}$, developed as described in our previous paper, compared favorably with Sitka spruce (Sp) for musical instrument soundboards with regard to density, $\rho$, and Young's modulus in the direction along the fibers, i.e., in the longitudinal $(L)$ direction [1]. An experimental guitar was built using this composite as shown in Fig. 1. However, the composite was inferior to Sp in Young's modulus in the direction across the fibers, i.e., in the radial $(R)$ direction. Young's modulus in the $R$ direction, $E_{\mathrm{R}}$, in $(\mathrm{CF} / \mathrm{UF})_{\mathrm{L}}$ composite is determined by the Young's modulus of the polyurethane foam matrix, $E_{\mathrm{m}}$, which is dependent on density. As low density is necessary for soundboard materials, the $E_{\mathrm{R}}$ cannot be improved by increasing the density of the polyurethane foam. Therefore, in the present study, we made a composite, $(\mathrm{CF} / \mathrm{UF})_{\mathrm{LR}}$, in which the $R$ direction was reinforced with carbon fibers.

\section{Design and production of composites}

Composites were produced by lamination of three symmetrical layers, i.e., a surface layer reinforced with carbon fibers oriented in the $L$ direction, a second layer reinforced with carbon fibers oriented in the $R$ direction, and a neutral layer of polyurethane foam. The $(\mathrm{CF} / \mathrm{UF})_{\mathrm{LR}}$ composite produced in this study is shown in cross-section in Fig. 2. First, an equation for calculating the Young's modulus of this composite, $E_{\mathrm{c}}$, was derived:

$$
\begin{aligned}
& E_{\mathrm{c}}=\frac{I_{0}}{I_{\mathrm{c}}} \cdot E_{0}+\frac{I_{1}}{I_{\mathrm{c}}} \cdot E_{1}+\frac{I_{2}}{I_{\mathrm{c}}} \cdot E_{2} \\
& I_{0}=\frac{1}{12} \cdot w \cdot t_{0}^{3} \\
& I_{1}=I_{\mathrm{c}}-\left(I_{0}+I_{2}\right) \\
& I_{2}=\frac{1}{12} \cdot w \cdot\left\{\left(t_{0}+t_{2}\right)^{3}-t_{0}^{3}\right\} \\
& I_{\mathrm{c}}=\frac{1}{12} \cdot w \cdot\left(t_{0}+t_{1}+t_{2}\right)^{3}
\end{aligned}
$$

where $E$ is Young's modulus, $I$ is the geometrical moment of inertia, $t$ is thickness, $l$ is length, $w$ is width, and subscripts c and $0-2$ represent composite and each layer, respectively. After substituting target values into $E_{\mathrm{c}}[1,2]$, the $E_{1}$ and $E_{2}$ values were calculated from Eqs. (1)-(5). Then, the volume fraction of carbon fibers in layer $1, V F_{\mathrm{f} 1}$, that in layer $2, V F_{\mathrm{f} 2}$, and the amount of polyurethane resin were computed using the law of mixtures on Young's modulus of a composite.

The procedure for the production of $(\mathrm{CF} / \mathrm{UF})_{\mathrm{LR}}$ composites and the cross-section of the mold with carbon fibers set are shown in Fig. 3. The conditions for manufacture of a (CF/ UF) $)_{\text {LR }}$ composite sample, designated D10B, are shown in Table 1. The sample D10B had dimensions of $610(l) \times$ $440(w) \times 3(t) \mathrm{mm}$, suitable for use in production of guitar top plates. For comparison, the composite sample L2S measuring $300(l) \times 300(w) \times 3(t) \mathrm{mm}$ with two symmetrical layers, in which only the surface layer was reinforced unidirectionally with carbon fibers, is also shown in Table 1. Sizing attached to the carbon fibers was washed off using chemicals to enhance the orientation of the carbon fibers and the penetrability of polyurethane resin into the carbon fiber strands. Thin strands $1 / 4$ of the width of those extending in the $L$ direction were laid in the $R$ direction to obtain a uniform distribution of a small quantity of fibers. Specimens measuring $105(l) \times 105(w) \times 3(t) \mathrm{mm}$ were cut from the CF/UF sample boards, and their vibrational properties and frequency response characteristics were measured by a flexural or torsion vibration method and a frequency sweep method with excitation at the center, respectively. The detailed techniques used for measurement were as described in our previous paper [1]. 


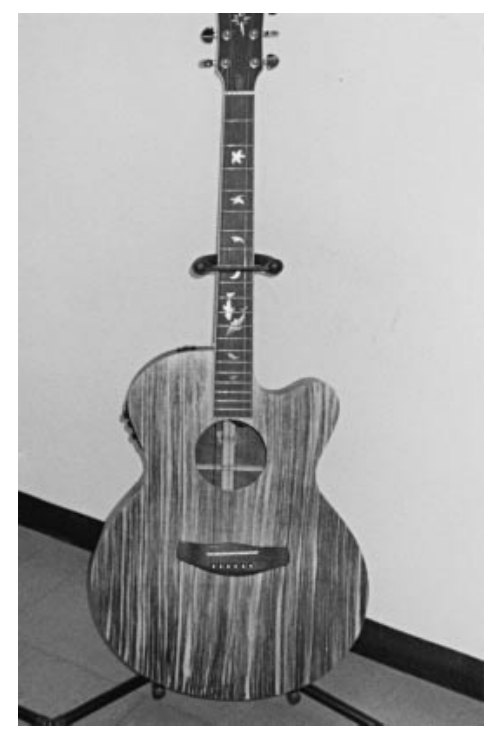

Fig. 1 The experimental guitar built using $(\mathrm{CF} / \mathrm{UF})_{\mathrm{L}}$ composite.

\section{Results and discussion}

The vibrational properties of $\mathrm{CF} / \mathrm{UF}$ composites and Sitka spruce are shown in Table 2 where $Q^{-1}$ is the internal friction and $G$ is the shear modulus. The power spectra and the $1 / 3$ octave band power spectra of $(\mathrm{CF} / \mathrm{UF})_{\mathrm{LR}} \mathrm{D} 10 \mathrm{~B}$ and $(\mathrm{CF} /$ $\mathrm{UF})_{\mathrm{L}} \mathrm{L} 2 \mathrm{~S}$ in comparison with those of Sitka spruce are shown in Figs. 4 and 5, respectively. In $(\mathrm{CF} / \mathrm{UF})_{\mathrm{LR}}$ sample D10B, both $E_{\mathrm{R}}$ and $G_{\mathrm{LR}}$ were enhanced keeping the density low and were almost the same as those of Sitka spruce. Comparison with the values for $(\mathrm{CF} / \mathrm{UF})_{\mathrm{L}}$ sample L2S showed that they were markedly improved in D10B. The figure shows that the frequency response of D10B was very similar to that of Sitka spruce and agreed with the results shown in the Table. Although the $E_{\mathrm{R}}$ of D10B was lower than that of $\mathrm{Sp}$, the $f_{\mathrm{R}}$ of D10B was higher than that of Sp. This was because D10B $(t=3.30 \mathrm{~mm})$ was thicker than the Sp sample $(t=3.03 \mathrm{~mm})$.

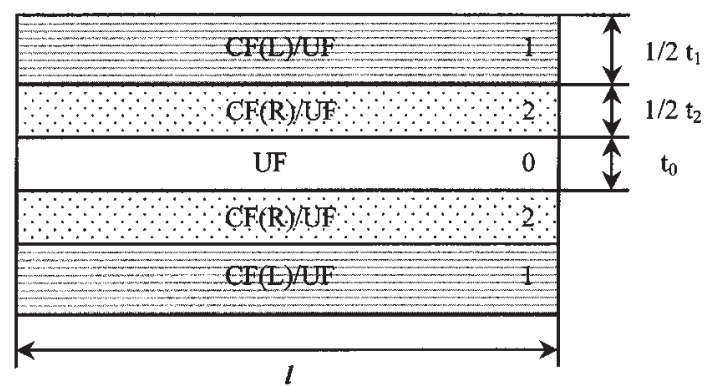

Fig. 2 Cross-section of $(\mathrm{CF} / \mathrm{UF})_{\mathrm{LR}}$ composite with three symmetrical layers. Numbers 0-2 indicate each layer of laminate.
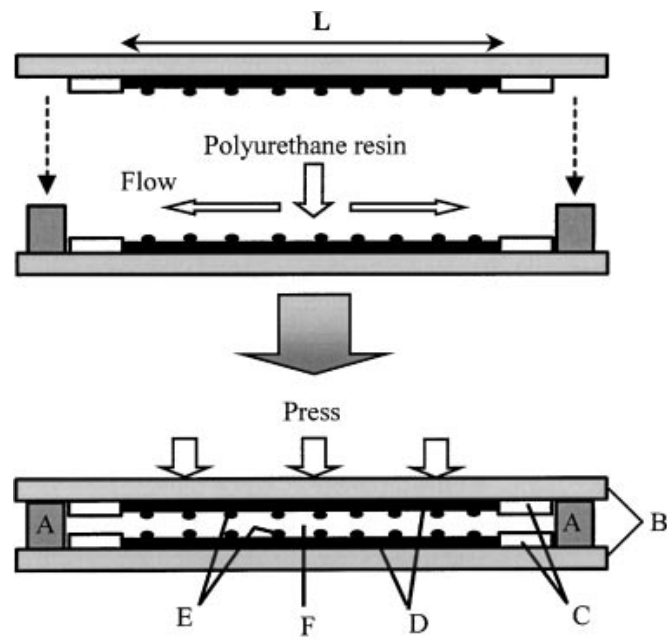

Fig. 3 The procedure for making the $(\mathrm{CF} / \mathrm{UF})_{\mathrm{LR}}$ composite sample and the cross-section of the mold with carbon fibers set. A, Aluminum frame (thickness = $3 \mathrm{~mm}$ ); B, Aluminum plate; C, Double-faced tape for adhesion of carbon fiber strand ends onto aluminum plates; D, Carbon fibers in the $L$ direction; E, Carbon fibers in the $R$ direction; $\mathrm{F}$, Polyurethane foam.

Table 1 Making condition of CF/UF composites.

\begin{tabular}{|c|c|c|c|c|c|c|c|c|c|c|}
\hline \multirow{3}{*}{ Samples } & & \multicolumn{6}{|c|}{ Materials } & \multicolumn{3}{|c|}{ Composites } \\
\hline & & \multicolumn{3}{|c|}{ Fiber } & \multicolumn{3}{|c|}{ Matrix } & \multirow{2}{*}{$\begin{array}{c}\rho_{\mathrm{c}} \\
\mathrm{g} / \mathrm{cm}^{3}\end{array}$} & \multirow{2}{*}{$\begin{array}{c}E_{\mathrm{Lt}} \\
\mathrm{GPa}\end{array}$} & \multirow{2}{*}{$\begin{array}{l}E_{\mathrm{Rt}} \\
\mathrm{GPa}\end{array}$} \\
\hline & & $\rho_{\mathrm{f}}\left(\mathrm{g} / \mathrm{cm}^{3}\right)$ & $E_{\mathrm{f}}(\mathrm{GPa})$ & $V F_{\mathrm{f}}(\%)$ & $\rho_{\mathrm{m}}\left(\mathrm{g} / \mathrm{cm}^{3}\right)$ & $E_{\mathrm{m}}(\mathrm{GPa})$ & $V F_{\mathrm{m}}(\%)$ & & & \\
\hline CF/UF D10 B & $\begin{array}{l}\text { (L) } \\
\text { (R) }\end{array}$ & 1.74 & 228 & $\begin{array}{l}5.00 \\
2.07\end{array}$ & 0.339 & 0.392 & 92.9 & 0.438 & 16.8 & 1.01 \\
\hline CF/UF L2 S & & 1.74 & 228 & 6.33 & 0.325 & 0.370 & 93.7 & 0.414 & 21.3 & 0.398 \\
\hline
\end{tabular}

VF: volume fraction, f: carbon fiber, m: matrix of polyurethane foam, t: value calculated by law of mixture, L: direction along grain, $\mathrm{R}$ : direction across grain.

Table 2 Vibrational Properties of CF/UF composites.

\begin{tabular}{|c|c|c|c|c|c|c|c|c|c|c|c|c|c|c|}
\hline Specimens & $\begin{array}{c}\rho \\
\mathrm{g} / \mathrm{cm}^{3}\end{array}$ & $\begin{array}{c}\rho / \rho_{\mathrm{c}} \\
\%\end{array}$ & $\begin{array}{l}f_{\mathrm{L}} \\
\mathrm{Hz}\end{array}$ & $\begin{array}{c}E_{\mathrm{L}} \\
\mathrm{GPa}\end{array}$ & $\begin{array}{c}E_{\mathrm{L}} / E_{\mathrm{Lt}} \\
\%\end{array}$ & $\begin{array}{l}Q_{\mathrm{L}}^{-1} \\
\times 10^{-3}\end{array}$ & $\begin{array}{l}f_{\mathrm{R}} \\
\mathrm{Hz}\end{array}$ & $\begin{array}{c}E_{\mathrm{R}} \\
\mathrm{GPa}\end{array}$ & $\begin{array}{c}E_{\mathrm{R}} / E_{\mathrm{Rt}} \\
\%\end{array}$ & $\begin{array}{l}Q_{\mathrm{R}}{ }^{-1} \\
\times 10^{-3}\end{array}$ & $\begin{array}{c}E_{\mathrm{L}} / \rho \\
(\mathrm{km} / \mathrm{s})^{2}\end{array}$ & $E_{\mathrm{L}} / E_{\mathrm{R}}$ & $\begin{array}{l}G_{\mathrm{LR}} \\
\mathrm{GPa}\end{array}$ & $E_{\mathrm{L}} / G_{\mathrm{LR}}$ \\
\hline CF/UF D10 B & 0.432 & 96 & 1654.6 & 12.6 & 75 & 5.21 & 487.2 & 1.09 & 108 & 7.27 & 29.2 & 11.6 & 0.831 & 15.2 \\
\hline CF/UF L2 S & 0.408 & 99 & 1742.2 & 13.5 & 63 & 6.40 & 303.4 & 0.408 & 103 & 17.6 & 33.1 & 33.1 & 0.378 & 35.7 \\
\hline $\mathrm{Sp}$ & 0.487 & & 1405.4 & 11.8 & & 8.82 & 459.4 & 1.29 & & 14.4 & 24.2 & 9.15 & 0.869 & 13.6 \\
\hline
\end{tabular}

LR: plane with edge grain. 

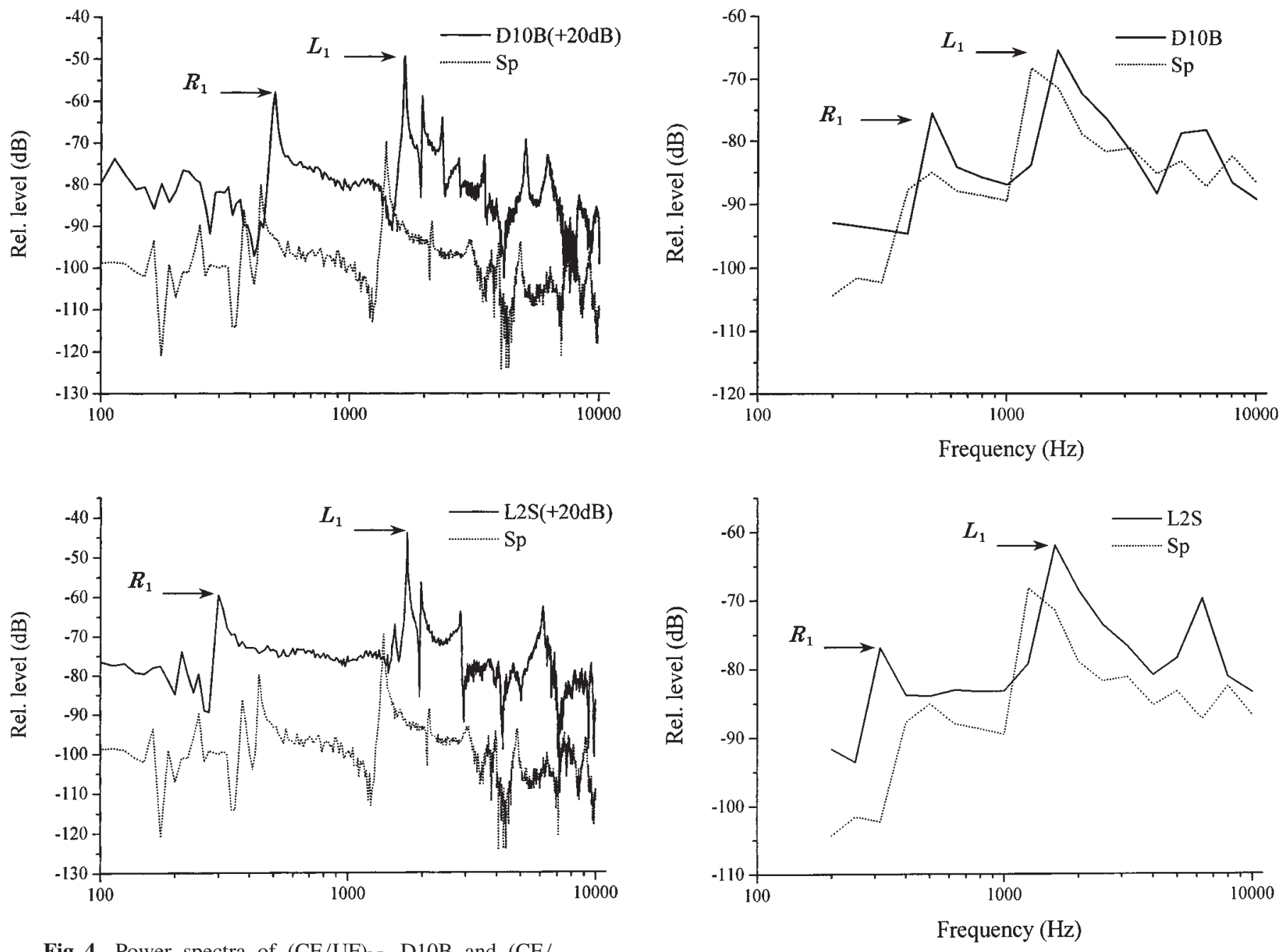

Fig. 4 Power spectra of $(\mathrm{CF} / \mathrm{UF})_{\mathrm{LR}} \mathrm{D} 10 \mathrm{~B}$ and $(\mathrm{CF} /$ UF) $)_{L}$ L2S compared with Sitka spruce by the frequency sweep method. Dotted line, Sitka spruce wood. Arrows $L$ and $R$ indicate the resonance point at the first mode in the $L$ direction and that in the $R$ direction, respectively.

Thus, a composite with acoustic characteristic very similar to those of Sitka spruce was obtained by reinforcing not only the $L$ direction but also the $R$ direction. In $\mathrm{L} 2 \mathrm{~S}$, the measured value of $E_{\mathrm{L}}$ was lower than the calculated value $E_{\mathrm{Lt}}$, $E_{\mathrm{L}} / E_{\mathrm{Lt}}=63 \%$. On the other hand, the measured value of $E_{\mathrm{R}}$ agreed well with $E_{\mathrm{Rt}}$. Analysis of the cross-section of the composite revealed that the fibers were situated not in the surface layer but in the inner layer. As bending stress is strongest on the surface, $E_{1}$ is best reflected in $E_{\mathrm{c}}$. Therefore, the lower $E_{\mathrm{L}}$ value described above was due to the slackness of the fibers. In D10B, designed to reduce fiber slackness, the measured value $E_{\mathrm{L}}$ was markedly enhanced, $75 \%$ of $E_{\mathrm{Lt}}$, and agreed with the above interpretation.

The composite with three symmetrical layers, reinforced with perpendicularly intersecting fibers, showed reduced fiber slackness and good penetrance of polyurethane resin into the carbon fiber strands. Our results indicated that Eqs. (1)-(5) deduced by the authors are useful for the design of composites with three symmetrical layers reinforced with fibers. The composite developed in this study is expected to be useful as a

Fig. 5 1/3-Octave band power spectra of $(\mathrm{CF} / \mathrm{UF})_{\mathrm{LR}}$ D10B and $(\mathrm{CF} / \mathrm{UF})_{\mathrm{L}} \mathrm{L} 2 \mathrm{~S}$ compared with Sitka spruce. Dotted line and arrows are the same as in Fig. 4.

material for musical instrument soundboards. However, some peaks that are not observed in wood were detected at frequencies above the second peak $\left(L_{1}\right)$, and further studies are required to resolve this problem. In future research, we will investigate the transient response, and will attempt to make larger plane boards and curved boards for use in pianos and violins, respectively, and will apply this new material to practical musical instruments.

\section{Acknowledgments}

We would like to express our gratitude to Yamaha Co. for the experimental guitar production and to BASF INOAC Polyurethanes Ltd. for their help in making the $\mathrm{CF} / \mathrm{UF}$ composites.

\section{References}

[1] T. Ono, S. Miyakoshi and U. Watanabe, "Acoustic characteristics of unidirectionally fiber-reinforced polyurethane foam composites for musical instrument soundboards," Acoust. Sci. \& Tech., 23, 135-142 (2002).

[2] N. H. Fletcher and T. D. Rossing, The Physics of Musical Instruments (Springer-Verlag, New York, 1998), pp. 719-723. 